\title{
Prenociones de la temporalidad en los niños*
}

\author{
Prenotions of temporality in children
}

\author{
Jessica Valeria Sánchez López** \\ ORCID: 0000-0002-5699-1304 \\ Universidad de Manizales, Colombia \\ Francia Restrepo de Mejía \\ ORCID: 0000-0002- 0352-0234 \\ Universidad Autónoma de Manizales, \\ Colombia
}

Recibido: 12 de septiembre de 2017

Revisado: 20 de noviembre de 2017

Aceptado: 2 de febrero de 2018

\section{Resumen}

Objetivo: El propósito de este artículo consistió en la elaboración de una hipótesis sobre el desarrollo de prenociones de la temporalidad en el niño, como procesos previos a la elaboración de la temporalidad que supone la incorporación de la duración y la sucesión. Metodología: revisión documental y lectura hermenéutica de los autores. Resultados: Las prenociones se relacionan con los ciclos del sueño y del hambre, inscritos en los ritmos circadianos, regidos por sistemas neurológicos que se acoplan hasta regularizar una rutina que permite la construcción de la noción de la temporalidad, mediante el ciclo relacional, construido en la corteza cerebral, con el aporte del sistema biológico, psíquico y social. Conclusiones: las prenociones de la temporalidad se ligan inicialmente a los procesos cíclicos controlados

Artículo de investigación. Este es un artículo derivado del proyecto de investigación titulado: la construcción de la temporalidad en niños y niñas con VIH, desarrollado en el marco del Doctorado en Ciencias Sociales, Niñez y Juventud de la Universidad de Manizales y el Centro de Estudios Avanzados en Niñez y Juventud (CINDE) acreditado en alta calidad. La investigación inició en junio de 2013 y terminó en noviembre de 2016. Se contó con la tutoría de la investigadora Francia Restrepo de Mejía, Ph.D. en Ciencias Sociales, Niñez y Juventud; Magíster en neurociencia y biología del comportamiento; y la asesoría del investigador Carlos Eduardo Vasco, Ph.D. en Matemáticas y Magister en Física de Saint Louis University; Doctor H. C. de la Universidad Nacional de Colombia. DOI: https://doi.org/10.15332/s1794-9998.2018.0002.12

Correspondencia: Jessica Valeria Sánchez López, Universidad de Manizales y el Centro de Estudios Avanzados en Niñez y Juventud (CINDE). Magíster en Desarrollo Infantil y Psicóloga de la Universidad de Manizales, Caldas, Colombia. Coordinadora de la Unidad de Investigaciones del Programa de Psicología de la Universidad de Manizales. Vinculada al grupo de Psicología Clínica y Procesos de Salud. Dirección postal: Calle 47 \# 30 -07 Barrio Colombia; Manizales, Colombia. Correo electrónico: jsanchez@umanizales.edu.co 
por sistemas neurológicos altamente diferenciados que se acoplan con los ciclos relacionales del afecto y del juego.

Palabras clave: temporalidad, tiempo, prenociones, niño, proceso psicológico.

\begin{abstract}
Objective: To create hypotheses about the development of preconceived notions of the temporality in children, as processes that come before the elaboration of the temporality that includes duration and succession. Methodology: documentary review and hermeneutic reading of literature. Results: The preconceived notions are related to sleep and hunger cycles, registered in circadian rhythms, controlled by neurological systems that are connected to regularize a routine that allows the construction of the notion of temporality, through the relational cycle, built in the cerebral cortex, with the contribution of the biological, psychic and social system. Conclusions: the preconceived notions of temporality are initially linked to cyclical processes controlled by highly differentiated neurological systems that are fit together with the relational cycles of affect and play.
\end{abstract}

Keywords: temporality, time, preconceived notions, child, psychological process.

\section{Introducción}

El objetivo general de la investigación fue comprender como construyen la temporalidad los niños y niñas, y el objetivo específico que dio origen al presente artículo fue el de identificar la influencia del sistema psíquico en la construcción de la temporalidad en los niños con $\mathrm{VIH}$; entendiendo que el sistema psíquico involucra los procesos psicológicos como sensación, percepción, memoria, atención, entre otros (Sánchez, 2017).

Las ideas que se tienen del tiempo en la actualidad son muy lejanas a las que tenían las personas de la edad media o de la antigüedad. El sol ha sido siempre el gran cronómetro en el mundo de los humanos, hasta que en Europa se instalaron en los siglos XIV y XV los relojes públicos, a partir de la instalación del reloj en la torre de San Eustorgio en Milán, en 1309. Luego, a finales del siglo XIV, en París se habían instalado la del Palacio y la del Castillo de Vincennes (Gómez, 2014). El reloj público solía ubicarse en la torre de la iglesia, de modo que la hora siempre era local. Solo en 1840 , se estableció en Londres la llamada "hora ferroviaria", por la necesidad de coordinar los horarios de los trenes entre ciudades (Rowlatt, 2014). De modo que el transporte fue el gran modificador de la noción de tiempo local de la edad media.

Hoy, los relojes se sincronizan según la hora nacional y en algunos países, como en Estados Unidos, según la hora del este, del centro o del oeste del país. Los smartphones se conectan por la red de telecomunicaciones de manera automática al sistema horario en el que están ubicados, de modo que no es preciso mirar el sol para cuadrar el reloj. Sin embargo, muchos campesinos en la actualidad del siglo XXI siguen viviendo en un mundo plano y en un tiempo local.

Como lo plantea Sánchez, Vasco, y Restrepo (2017) en este mundo, las nociones del tiempo se forman en los niños según su cultura y las percepciones sociales del tiempo. En todo caso, hay nociones que el niño va construyendo de acuerdo con la 
evolución de su capacidad de construir la temporalidad, que no aparecen de manera espontánea y que requiere procesos operativos complejos (Sánchez, 2017).

El propósito de este artículo consiste en la elaboración de una hipótesis sobre el desarrollo de prenociones de la temporalidad en el niño, como procesos previos a la elaboración de la temporalidad que supone la incorporación de la duración y la sucesión. Las prenociones a las que se refiere este texto se relacionan con los ciclos temporales que ocurren desde el nacimiento y que se inscriben en los ritmos circadianos que, por sí solos, no constituyen una experiencia temporal, puesto que los retornos cíclicos no permiten elaborar la noción de sucesión ni de duración.

Adoptamos de Vasco (2000) el término temporalidad para referirnos a lo que en los libros de física y algunos autores como Piaget (1978) llaman tiempo, para referirnos al campo de estudio de la psicología. Con una perspectiva física y con una racionalidad matemática, Vasco (2000) distingue seis acepciones del tiempo: la temporalidad, relacionada con la dinamicidad que permite pensar que hay un antes y un después; la Duración (con mayúscula) como la magnitud física; el lapso como la "estructura topológica sobre ese continente vacío que abstraemos de los procesos cuando consideramos los lapsos que duran los procesos" (Vasco, 2000, p. 231) y da origen al "tiempo cronológico"; la equidurancia, como estructura de equivalencia que proviene de las medidas del tiempo (años, días, horas, segundos); la estructura ordinal del tiempo que Vasco toma de Carlo Federici Cassa, que deriva del reconocimiento de las propiedades reflexiva, antisimétrica y transitiva de los lapsos; y la coordinatización, como la compaginación temporal de los eventos y los fenómenos, que puede ser observado como cronotopía, es decir, como reunión del espacio y del tiempo en la observación del espacio-tiempo de los procesos y los fenómenos.

Vamos a esbozar aquí algunas de estas representaciones que pueden manifestarse en la construcción de la noción del tiempo en los niños, y que los estudios de autores como Piaget no abordan por considerar que la elaboración de la noción del tiempo en los niños es la aproximación al concepto de tiempo de la física:

Pero la noción de tiempo no interesa solamente a la psicología del pensamiento en cuanto se relaciona con el desarrollo de los conceptos científicos. Toda la filosofía de Bergson, así como los innumerables trabajos que, en psicología propiamente dicha, han sido influidos por aquella, han evidenciado la importancia de los conceptos de duración interior y de tiempo psicológico (Piaget, 1978, p. 9).

En esta forma, Piaget reconoce la validez de abordar otras nociones del tiempo que no se refieren estrictamente a los conceptos científicos, lo que autoriza a hablar, por una parte, de esas representaciones, y por otra parte, precisar la noción del tiempo como temporalidad.

Para Piaget (1978) el tiempo y el espacio son inseparables, y si el espacio suele ser considerado en forma independiente, no ocurre lo mismo con el tiempo, que solo es pensable de manera independiente en circunstancias especiales.

El espacio es un algo instantáneo captado en el tiempo, y el tiempo es el espacio en movimiento; ambos constituyen, en su reunión, el conjunto de relaciones de concatenación y de orden que caracterizan a los objetos y sus movimientos (p. 12)

No obstante, es más fácil hacer una abstracción del espacio como algo independiente del tiempo, como ocurre en la geometría, que hacer una abstracción del espacio de tal forma que su objeto de estudio no considera el tiempo y el espacio es concebido de manera independiente, en forma abstracta, puesto que las formas que define solo existen como nociones de la geometría y no se refieren a fenómenos empíricos.

Pero si puede aislarse el espacio y hacerse abstracción del tiempo para construir las relaciones geométricas (basta colocarse en el punto de vista de una simultaneidad ficticia y describir los movimientos como meros desplazamientos con velocidades infinitas, 
o independientes de sus velocidades), no se puede, en cambio, aislar el tiempo y hacer abstracción, para elaborarlo, de las relaciones espaciales y cinemáticas, es decir, de las velocidades. Por consiguiente, solo una vez construido el tiempo puede ser concebido como un sistema independiente, y aún ello no resulta posible sino a velocidades pequeñas. Durante la construcción, el tiempo permanece, al contrario, como una simple dimensión, inseparable de las dimensiones espaciales, y solidaria de esta coordinación de conjunto que permite reunir, unas con otras, las transformaciones cinemáticas del universo (Piaget, 1978, p. 13).

De esta manera, es probable que la elaboración de la noción de la temporalidad se de a la par con la noción de espacio en sus tres dimensiones, lo cual permitirá la intuición de la dinamicidad. Ese tiempo intuitivo es precedido por la sucesión y la duración (con minúscula, según Vasco), que Piaget llama tiempo operativo.

Si ese es el caso, el estudio de la génesis de la noción de tiempo puede ser muy instructivo por lo que hace a la naturaleza de esta categoría fundamental del espíritu. Si el tiempo es realmente la coordinación de los movimientos, en el mismo sentido que el espacio es la lógica de los objetos, hay que esperar que exista un tiempo operativo, que consiste en relaciones de sucesión y de duración fundadas sobre operaciones análogas a las operaciones lógicas. Este tiempo operativo será distinto del tiempo intuitivo, limitado a las relaciones de sucesión y de duración dadas en la percepción inmediata, externa o interna. El tiempo operativo podrá ser en sí mismo cualitativo o métrico, según que las operaciones que lo constituyen permanezcan análogas a las de las clases y relaciones lógicas, o que hagan intervenir una unidad numérica. Hay que atenerse, sobre todo y si tal es el caso, a que el tiempo intuitivo resulta insuficiente para constituir relaciones adecuadas de simultaneidad o sucesión y de duración... (p. 12)

Esto implica que noción de temporalidad se elabora sobre el tiempo operativo, de modo que la intuición de las propiedades de durabilidad, y de sucesión o simultaneidad se construye sobre operaciones prácticas en las que esas propiedades se manifiestan como operaciones, y en relación con la posibilidad de aislar las dimensiones espaciales.

El propósito de este artículo consiste en la elaboración de una hipótesis sobre el desarrollo de prenociones de la temporalidad en el niño, como procesos previos a la elaboración de la temporalidad que supone la incorporación de la duración y la sucesión.

\section{Metodología}

La metodología de la investigación implicó procesos creativos, individualizados y reconfiguraciones múltiples; los resultados de la investigación muestran que los niños necesitan voz, en espacios distintos al influjo de los adultos.

El diseño contó con dos niveles de abstracción; un primer nivel descriptivo y un segundo nivel comprensivo, cada nivel contó con cuatro marcos de observación, a saber, marco teórico, marco empírico, marco epistemológico y marco metodológico.

En los marcos se tuvieron que hacer selecciones y establecer límites. Así, en el marco teórico se seleccionaron autores, libros y artículos; en el marco empírico se seleccionó la unidad de trabajo, tres niños y dos niñas. En el marco epistemológico, se seleccionó la hermenéutica; y en el marco metodológico se seleccionó el método de estudio de caso en la lógica de Sara Merriam (1988) y de Robert Stake (1994; 1995;1998), quienes asumen el estudio de caso como una exploración de un sistema ligado a un caso o a múltiples casos, a través de una recolección de datos detallada que incluye varias fuentes de información.

De las fuentes o técnicas para obtener información de las que se vale el estudio de caso, se seleccionaron la revisión de documentos, la revisión y lectura hermenéutica de los autores, la entrevista a los actores y a los autores y los diarios de vida (Cole, 1994). 
Figura 1. Los cuatro marcos.

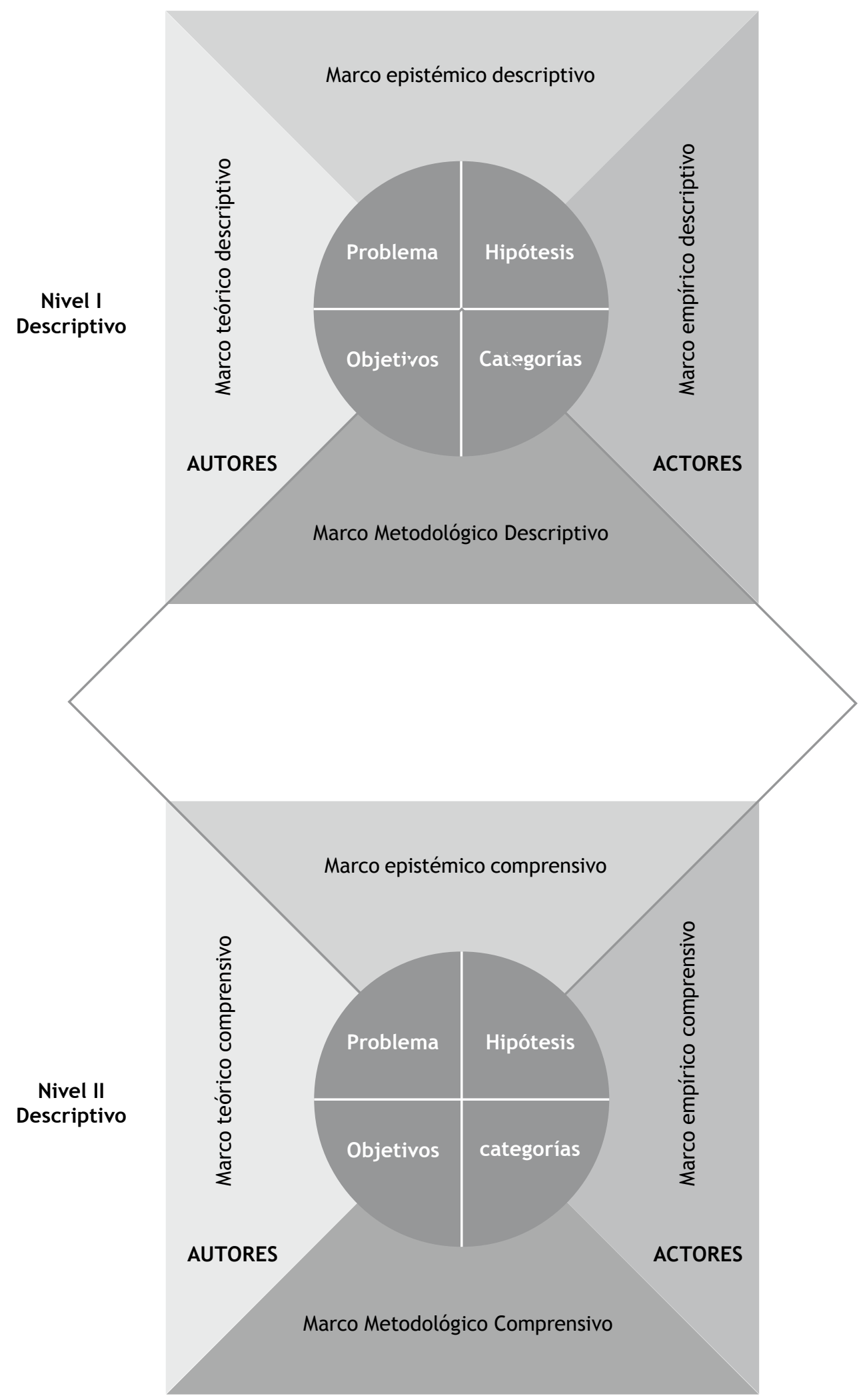

Fuente: Sánchez (2017) 


\section{Desarrollo del tema}

La primera acepción del tiempo propuesta por Vasco (2000) es la temporalidad, cuya terminación "dad" alude a la propiedad de algo, en este caso, de la dinámica de los procesos y los fenómenos.

Una primera acepción de la palabra "tiempo" es pues la temporalidad como propiedad inherente a todo proceso, relacionada con la dinamicidad. Es aquello que nos permite decir de los procesos que fluyen, duran, corren, discurren [y agrega con sarcasmo, en un leitmotiv que va apareciendo en cada acepción tratada y que indica su carácter intuitivo]: quien no tenga intuición inmediata de su experiencia interna del fluir de la conciencia no puede entender lo que estamos diciendo. Con esa persona no podríamos hablar del tiempo. En realidad, con esa persona no podríamos hablar (p. 224).

El autor se refiere entonces, a la intuición del fluir de los fenómenos y de la conciencia de ellos. La necesidad que él encuentra de distinguir las acepciones del tiempo es la necesidad de precisar un concepto que suele ser difuso.

Seamos conscientes de que a veces hablamos del tiempo como la temporalidad de los procesos y los fenómenos; a veces como la estructura temporal de la totalidad de los procesos y de los fenómenos y de sus clases de equivalencia; a veces como el continente o recipiente vacío en el que ellos ocurren, con su estructuración topológica; a veces como la duración de los mismos al menos de dos maneras diferentes que precisaremos más tarde, y a veces como coordinatización de algún fenómeno del inicio o terminación de algún proceso (p. 224)

La adopción del término temporalidad permite, entonces, precisar el concepto que en la palabra tiempo se diluye por su generalidad y por la variedad de significados que se le han otorgado en la historia. El problema que se plantea Piaget (1964) consiste en que las nociones de espacio y de tiempo, y aún de los procesos inferenciales, no son, como en Kant
(2007), preexistentes en el sujeto sino construidos por este en su experiencia cognitiva. La perspectiva de Piaget polemiza con el idealismo kantiano que ubica el tiempo en el sujeto como juicio sintético a priori a la experiencia. También se opone al objetivismo que lo concibe como una propiedad del mundo independiente de los sujetos. Para Piaget, la evidencia de que el tiempo se construye se observa en las dificultades de los educadores "Por último, los educadores y la psicología pedagógica tropiezan sin cesar con los problemas que suscita la incomprensión del tiempo en los niños de edad escolar" (Piaget, 1978, pág. 10).

La duración de los fenómenos y los procesos se construyen, según Vasco, sobre la posibilidad de construir la noción de lapso, como duración particular de procesos y fenómenos concretos, lo que implica la posibilidad de traslape de dichos lapsos, que son fracciones de un lapso mayor. La equidurancia de los lapsos exige, según Vasco, los relojes. Un reloj, que aquí llamaremos cronómetro, es un aparato que marca lapsos iguales, de modo que permite medir en términos de los lapsos que marca, cuánto dura un fenómeno o un proceso sincronizado con este baremo. Cabe aquí pensar que un cronómetro solo puede medir los lapsos cuyo inicio se de en el presente, hasta su terminación. Pero no puede medir lapsos del pasado. De modo que el pasado no se puede medir, a menos que haya sido medido como presente. La comprensión de esta consideración es posible si se tiene en cuenta la temporalidad en su dinamicidad, en su fluir, si no se espacializa el tiempo.

Si un lapso, que Vasco (2000) presenta mediante la línea de tiempo, como metáfora espacial de la duración de un proceso o un fenómeno particular, se suma a otro lapso, el resultado es un lapso mayor que los dos anteriores, de modo que se puede hablar de una estructura ordinal del tiempo, que cumple con las tres propiedades de las estructuras de orden, que son la propiedad reflexiva, la propiedad antisimétrica y la propiedad transitiva. Vasco encuentra que la propiedad reflexiva es imposible de probar en los lapsos, pero sí es posible comprender que si un lapso $A$ es mayor que un lapso $B$, en ningún caso el lapso $B$ puede ser mayor que el lapso $A$. $Y$ respecto a la propiedad 
transitiva, si el lapso A dura más que el lapso B y el lapso $B$ dura más que el lapso $C$, entonces, el lapso A dura más que el lapso C (Vasco, 2000). Ahora bien, la duración de los lapsos, si no se observan en el presente, es preciso acudir al cronómetro para saber si los lapsos son mayores o menores uno respecto al otro, medido cada uno en su presente.

Esta acotación es necesaria en la dimensión temporal, porque no se trata de una estructura propiamente dicha, puesto que se trata de la temporalidad de los procesos y los fenómenos que deben ser abordados, por tanto, según Vasco, mediante la cronotopía, es decir, mediante la duración del espacio, es decir, en las dimensiones espacio-temporales que se conjugan en los procesos y los fenómenos.

Entre las formas en que los niños van construyendo su noción de la temporalidad, como imagen que transita en la sociedad, es su espacialización.

\section{La espacialización del tiempo}

Vasco comenta que una dificultad para hablar del tiempo es referirse a él en forma espacial, como una línea, como un recipiente vacío o como cualquier representación gráfica o figura de dos o de tres dimensiones. Para Vasco, la metáfora espacial del tiempo permite la construcción de la noción de lapso, puesto que la imagen del tiempo como una línea que puede ser una suma de lapsos, solo es posible mediante esa noción espacial de la dimensión distancia. Para Bergson (1972), en cambio, la dificultad consiste en que esta forma de referirse al tiempo dificulta su comprensión como fluir, como dinámica irrepetible. Podría decirse, de acuerdo con Bergson, que es la dificultad de concebir el tiempo como el transcurrir de los procesos que no puede ser descrito en un mapa sino en un relato que no puede ser contado sino una sola vez.

La metáfora que usa Bergson (1999) para referirse a la duración y a la memoria como forma de captar esa duración es el cinematógrafo. Cuando la película capta un proceso que dura, porque ocurre en su temporalidad, lo hace mediante fotogramas fijos que al pasar luego uno tras otro, dan la sensación de movimiento, pero el movimiento no ha sido captado como duración. Esto significa que la memoria se comporta como una espacialización de la duración en imágenes fijas, que tienen una representación en el espacio. Pero la mente humana no puede capturar directamente la duración (Ángel, 2015). Por esto, las prenociones de la temporalidad referida a la duración y a la sucesión pueden tener representaciones temporales y la intuición de la temporalidad no captura directamente la duración, aunque puede distinguir la sucesión.

Ahora bien, como el espacio suele invadir las representaciones del tiempo, en la formación de la noción de la temporalidad se manifiestan formas de espacialización que los niños expresan de diferentes maneras. Esa sensación de recipiente que se llena es una forma de entender el tiempo y de la cual es consciente Piaget (1978):

El objeto de esta primera parte es situar el desarrollo de la idea de tiempo en el contexto cinemático, fuera del cual esta noción carece de significación. Hay una fuerte tendencia, en efecto, a hablar de una intuición del tiempo o de conceptos temporales, como si el tiempo pudiese, a semejanza del espacio, ser percibido y concebido independientemente de los seres o de los acontecimientos que lo llenan. Así como el espacio aparece como una caja vacía en la cual son colocados los cuerpos, así el tiempo será como la película móvil en la que se graban los cuadros que se suceden en función de su desarrollo (p. 11).

En Piaget, la metáfora del cine se refiere a la imposibilidad de capturar el tiempo en sí mismo, puesto que la duración está referida a lo que dura, es decir, a la estructura que transita en la cinemática de los "seres o los acontecimientos" que duran. Para Piaget, entonces, el tiempo tampoco puede ser captado en sí mismo, fuera de aquello que transcurre en el tiempo, y por eso no puede pensarse sino ligado al espacio. En términos de Vasco, el tiempo solo puede ser percibido en forma cronotópica, porque existe en lo que dura. Todo pensamiento sobre el tiempo es, pues, una abstracción de la condición espacio temporal de 
las cosas y los procesos, de modo que las acepciones que relaciona Vasco, aparte de la temporalidad, son abstracciones relacionadas con las estructuras lógicas que estudia Vasco de manera pormenorizada.

Una pregunta sobre esta postura surge de la sospecha de que las concepciones espaciales del tiempo pueden no ser consideradas como errores de percepción puesto que en ellas puede haber más bien manifestaciones de aproximaciones sucesivas a una noción de la temporalidad de la física, o bien, expresiones socioculturales que remitan a formas de representar el mundo de herencias culturales que han penetrado muchas culturas, como puede ser el cristianismo, por ejemplo.

La propuesta de reflexión que se quiere dejar esbozada aquí parte de la sospecha de que en los niños hay elaboraciones anteriores a la de la temporalidad en la física, sobre las cuales van construyendo la noción relacionada con la dinamicidad de los fenómenos con los que tienen contacto en su experiencia.

\section{Los tiempos circulares}

El primero y más básico de los cronómetros es el sol que marca los lapsos del día y la noche y con ellos, en los seres vivos, los ciclos circadianos (Richter, Torres-Farfán, Rojas-García, Campino, Torrealba \& Serón-Ferré, 2004). Estos ritmos se dan por el acoplamiento entre el sistema biótico y el sistema mundo en la duración de un día, de donde proviene su nombre ${ }^{1}$. Este fenómeno universal de animales y plantas, determinado por el sol, ha provocado el acoplamiento de los sistemas bióticos que se han adaptado al ritmo de los intervalos de luz y oscuridad con expresiones orgánicas. En esta forma, los ciclos circadianos cobran independencia de la presencia o la ausencia de la luz del sol, y siguen un ritmo propio, de la misma duración. En el organismo humano, la glándula pineal que produce melatonina y regula los ciclos del sueño (Moore, 1996; Pinel, 2007) . Este reloj biológico, acoplado al reloj solar, es el primer cronómetro del recién nacido, cuyo ritmo de sueño

$\overline{1 \quad \text { Circa }=\text { acerca de }}$; dies, diei = día (del día, $5^{\mathrm{a}}$ decl. $)$. es mucho más acelerado que el de un ciclo circadiano, porque se encuentra acoplado a otro ciclo que es el del hambre.

En la figura 2 se representan dos ciclos biológicos del recién nacido, que se hacen sincronizar en el sistema de los ciclos circadianos del día y la noche biológicos. Los círculos naranja corresponden a un hipotético ciclo del sueño, y los círculos verdes serían las ocho vigilias de las que habla Vasco (2000), y corresponden al ciclo del hambre. Los dos ciclos se acoplan como dos sistemas que están regulados por centros neurológicos diferentes, el del sueño, por la glándula pineal y la producción de la melatonina (Valenzuela et al., 2008) y la regulación neuro-energética del hambre está regida por un sistema neuroendocrino redundante, integrado a nivel del hipotálamo (González, Ambrosio \& Sánchez, 2006). De modo que estos dos sistemas definen dos ciclos diferentes que producen sensaciones que el niño no identifica con claridad al principio, y que van cambiando con la edad.

No obstante, el ciclo del hambre y el ciclo del sueño no se sincronizan sino más tarde, de modo que en un recién nacido puede haber momentos en los que el niño no sabe si tiene hambre o sueño o, como se ve en la figura, puede haber momentos de traslape en los que el niño puede sentir simultáneamente hambre y sueño. La confusión que producen estos traslapes suele entorpecer la regulación de ambas sensaciones y el niño llora porque anuncia que tiene hambre, pero no puede comer porque se duerme mientras lo alimentan. 0 bien, llora porque tiene sueño, pero no distingue entre las dos sensaciones, de modo que puede creer que tiene hambre y pide comida (Buijs \& Kalsbeek, 2001; Van Essevelt, Lehmann \& Boer, 2000).

Los traslapes de los dos ciclos dan como resultado momentos de hambre sin sueño, momentos de sueño sin hambre, momentos de hambre y sueño y momentos sin hambre y sin sueño. Estos últimos dejan espacio para las interacciones y el juego, que se inscriben en los intersticios de los ciclos biológicos y que empiezan a liberar la conciencia hacia la construcción de la temporalidad, de la noción de espacio y de otras nociones estudiadas por Piaget (1964). 
Figura 2. Acoplamiento de ciclos biológicos.

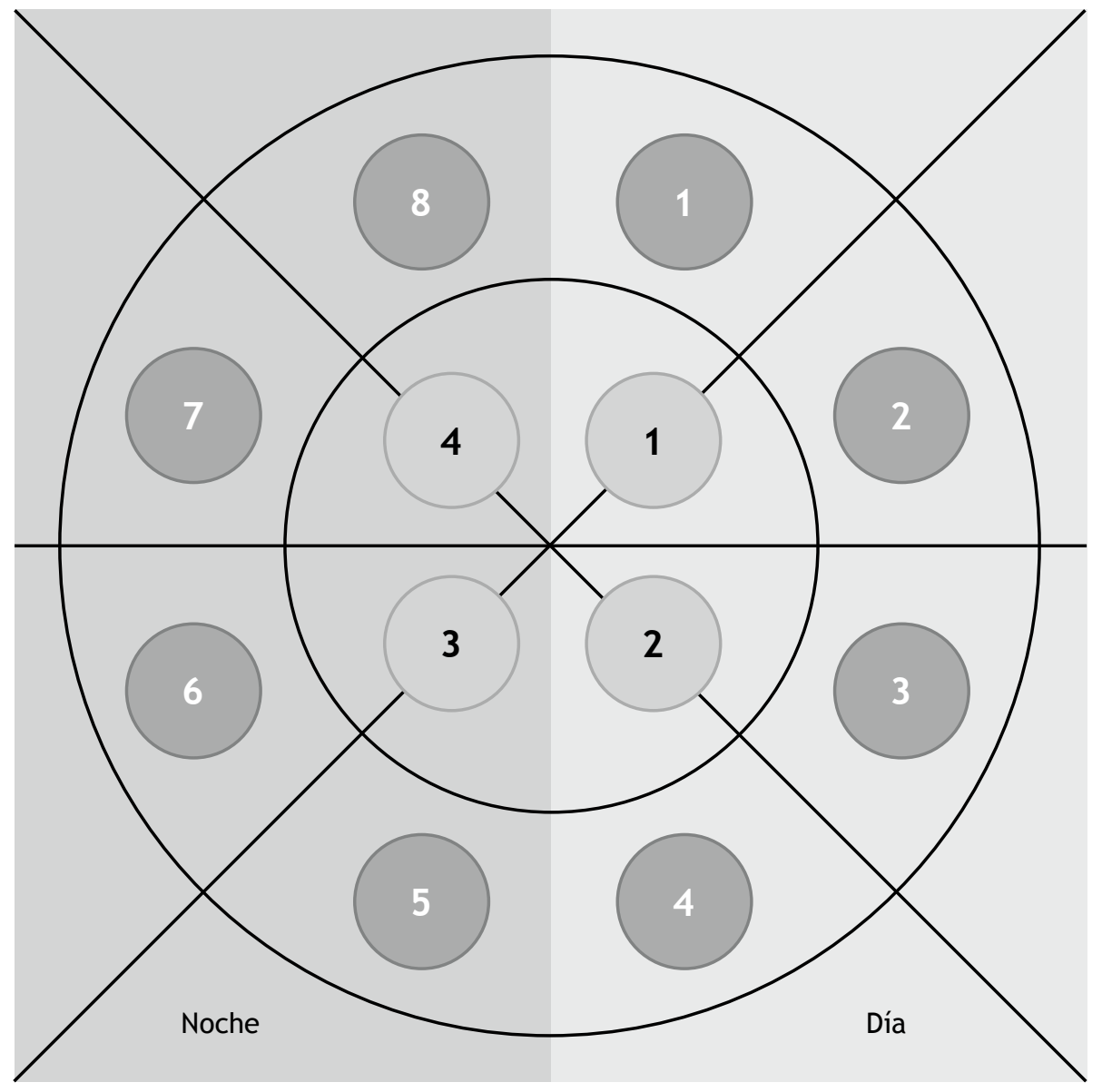

Fuente elaboración propia.

En todo caso, los momentos de hambre y de sueño se distancian con la edad y los dos ciclos se sincronizan en relación con los ritmos circadianos, dada la producción de la melatonina en la glándula pineal, lo que influye en la hipófisis y ésta en todos los sistemas del organismo (Attenburrow, Cowen \& Sharpely, 1996; Cassone, 1990; Moore, 1996). Entonces, el acoplamiento entre los sistemas neurológicos, que son autopoiéticos y tienen independencia operativa (Luhmann, 1998), permiten sincronizarse de una manera que el organismo puede operar de una manera armónica.

Ahora bien, los dos únicos ciclos no son el del hambre y el del sueño, pues en las vigilias, cuando el niño ya ha comido, suele haber unos tiempos de juego con la madre y con otros adultos, que van constituyendo otro ciclo de interacciones derivado de los dos anteriores. Este ciclo no es auto- mático, puesto que no solo depende de funciones orgánicas ligadas al sistema límbico sino a funciones superiores ligadas directamente a la corteza (Lavie, 2001; Saper, Chou \& Scammell, 2001) .

Los ciclos del hambre y del sueño, que van evolucionando hacia lapsos más largos, no evolucionan necesariamente hacia una sensación interna de sucesión ni de duración. Son círculos que retornan hacia la misma sensación, de modo que la circularidad detiene la temporalidad en una sensación binaria de hambre y saciedad o en una sensación binaria de sueño y vigilia. Solo el tercer ciclo que se mencionó arriba, el ciclo relacional, ofrece eventos nuevos que pueden ir rompiendo la circularidad de los ciclos ligados a los ritmos circadianos, aunque este círculo relacional ocurre en los intervalos de los otros dos ciclos. 


\section{La memoria de quien vino mañana}

Un capítulo aparte en la elaboración de las prenociones de la temporalidad lo conforma la memoria, como organización de las huellas mnésicas en el relato (Augé, 1998). Una de las primeras actividades que se despiertan con la adquisición del lenguaje es la necesidad de contar lo sucedido en el pasado reciente.

Los relatos de un niño de tres años, en un lenguaje aún en media lengua, suelen ser una mezcla de recuerdos y fantasía en la que pueden interactuar con tigres, diablos, y toda clase de quimeras que ingresan en la memoria en un tiempo que no transcurre en la vida sino en la dimensión de la imaginación (Ángel, 2015). Ocurren más en el "érase que se era" que en algún "ayer", y por eso los niños que empiezan a hablar pueden ubicar algún relato en un "mañana". Es decir, la prenoción de la temporalidad de este niño, que ocurre en el tiempo de la fantasía, no está ligada a la duración de los acontecimientos ordinarios, sino al tiempo que se comprime y se estira según las necesidades del relato.

Desde San Agustín de Tagaste, hay algunos autores que se ocupan del tiempo, como Spinoza, hasta Kant, en una tendencia subjetivista de esta noción. $Y$ después de la modernidad, es Bergson quien pone en el tinglado teórico este problema con una visión realmente novedosa. $Y$ es Bergson quien elabora una propuesta diferente a la aristotélica de la memoria (Bergson, 1999), puesto que la relaciona con la percepción del tiempo que no subsiste en la conciencia como duración sino como memoria, es decir, como sensación de la duración mediante imágenes estáticas.

La memoria, según Augé (1998), es el relato de las huellas. El autor utiliza la metáfora del hilo del collar que engarza las cuentas que son los recuerdos, y los recuerdos no son el acontecimiento mismo que quedó en el pasado y que es irrecuperable, sino el encadenamiento de las huellas. Este relato-memoria ubica un tiempo que ocurre en el tiempo del relato puesto que ocurre en el pasado inconmensurable. La memoria se refiere al pasado, así sea un pasado reciente, y el tiempo pasado no puede ser cronometrado ni referenciado con ningún baremo del tiempo presente. Por eso, la memoria tiende a apretar el tiempo en la duración del relato.

Ese tiempo del relato no es, pues, el tiempo histórico y el acontecimiento como referente de lo "realmente sucedido", que es la persecución del historiador que se basa en la memoria como testimonio de los acontecimientos, que son el referente del relato (Ricœur, 2004). Sin embargo, el relato memoria de los grupos humanos no tiene la pretensión de "dar cuenta" del acontecimiento, sino de interpretarlo, de modo que no hay que leer en él lo sucedido sino la apreciación de quienes relatan. $Y$ ese es también el relato del niño que cuenta historias en las que él intervino mañana o ayer o una vez. Las formas en que las fábulas infantiles suelen empezar son fórmulas de ese tiempo que transcurre en un tiempo ilusorio: "érase que se era" o bien "había una vez" son referencias temporales que huyen del tiempo de los relojes y del calendario. Son referencias temporales que aprietan los sucesos en un tiempo de fábula que no dura, y en el que suceden las cosas según las necesidades del relato.

En esta forma de relato memoria en el que la dimensión imaginaria de los niños está presente, se empieza a conformar una manera de elaborar la temporalidad, puesto que el relato es ya un transcurrir en un tiempo propio que indica una prenoción de la sucesión, más que de la duración. Los acontecimientos que el niño cuenta en el tiempo de la imaginación conforman una incorporación de un orden de los sucesos narrados que hacen alusión a lo que pasa antes y a lo que pasa después, de modo que la sucesión es precursora de la duración en la construcción de las prenociones de la temporalidad.

Es preciso agregar que esta forma de incluirse en un relato imaginario que conserva elementos del tiempo vivido interviene en la construcción de la identidad del niño que va construyendo el relato memoria de su propia idea de sí mismo, es decir, va construyendo un yo contado con el que el niño se identifica. Por eso, la memoria es un elemento clave de la identidad y por eso los autores que abordan el problema de la identidad de los grupos 
humanos se refieren siempre a su memoria o a sus modos de fabulación.

En esta segunda actividad, que nace con el lenguaje, se construyen los precursores de la noción de temporalidad en relación con la sucesión y la simultaneidad. Es mucho más difícil construir la temporalidad en relación con la duración de los sucesos que se cuentan, puesto que la sensación de los lapsos y de sus traslapes es más compleja y requiere que el relato adquiera una dimensión que la simple sucesión de hechos no tiene. Y la sucesión suele tener una representación espacial. De hecho, en los ejercicios que Piaget realiza con niños se suele hacer dibujar (representación espacial) lo que antecede y lo que sucede. Es decir, la noción de temporalidad suele acudir a representaciones espaciales del antes y el después.

\section{Conclusiones}

Aventurar la hipótesis de las prenociones de la temporalidad en los niños, antes de la formación de la noción de temporalidad permite comprender que esta noción, como intuición de la duración y la sucesión, aparece lentamente y es una premonición de la libertad que otorga la conciencia.

La circularidad de los ciclos del hambre y del sueño, ligados a los ritmos circadianos, se remite a las polaridades entre hambre-saciedad, y entre sueño-vigilia que regresan a la misma sensación y, por consiguiente, no produce la sensación de sucesión, puesto que el círculo retorna a lo mismo, de modo que la noción de sucesión queda suspendida en el retorno que es inexorable y no permite abrirse a la dinámica de procesos posibles y a la noción de temporalidad.

Solo la disposición de un tiempo del que el niño es dueño, el ciclo relacional que transcurre en los intersticios de estos ciclos y que hacen intervenir a la corteza en actividades de la conciencia que requieren una dinámica neuronal que supera los ciclos de la glándula pineal y del hipotálamo. Las prenociones que se elaboran en este rompimiento de la circularidad de los ciclos biológicos se refieren al tiempo libre y a los intervalos que son metáforas espaciales del tiempo, o mejor, prenociones espaciales del tiempo, puesto que no cumplen una función expresiva para alcanzar la categoría de metáfora.

Otro tanto ocurre con la memoria como relato que pretende dar cuenta de hechos que solo transcurren en el tiempo de la imaginación, pero que crean por la propia dinámica del relato la prenoción de un tiempo en el que las cosas suceden una después de otra. Esta dinámica del relato-memoria es, además, un principio de construcción de un relato identitario en el que se afianza el yo.

La noción de la temporalidad en sus características de duración y sucesión se monta sobre estas prenociones, que abren paso a la dinamicidad de los procesos y los fenómenos.La temporalidad como proceso psicológico surge con el aporte del sistema biológico (sistema nervioso), desde el acoplamiento estructural que se da entre los diferentes subsistemas del sistema biológico. El acoplamiento estructural es temporal, es acontecimiento, es simultaneidad y posibilita las referencias entre sistemas diferentes, el biológico, el psíquico y el social, al igual que entre los subsistemas de cada uno de los sistemas.

Para que un niño pueda comunicar su modelo de temporalidad requiere asociar la información en la corteza cerebral, específicamente en la corteza prefrontal, la cual le permite al niño ser consciente de sí mismo, del espacio y del tiempo.

La manera como cada niño construye las prenociones del tiempo es diferente; no es igual el tiempo en un niño que se siente enfermo (Del Palacio, Alvarez \& Muñoz, 2012; Foster,2003; Foster \& Lyall, 2005; Foster, Biggs, Melvin, Walters, Tudor \& Lyall, 2006; McCoig, Castrejon \& Castano, 2002; Smith, Malee \& Leighty, 2006; Smith et al., 2012;) al que no siente ningún síntoma físico ni emocional, y quizás es diferente en el niño que no tiene ninguna enfermedad crónica. Un enfermo, ante una situación difícil en el curso de su enfermedad, tiene la sensación de que el tiempo subjetivo es mayor que el tiempo cronológico (Bayés, 2000; 2001) y este es un indicador de malestar.

Por el contrario, cuando percibe que el tiempo pasa con rapidez, este fenómeno suele traducirse 
en un estado de bienestar (Gómez \& Grau, 2006; Grau, 2003; 2004; Llantá, Grau \& Massip, 2004; Llantá, Grau, Massip, Pire, Rivero \& Ortiz, 2005; Mendez \& Grau, 2003).

\section{Referencias}

Agustín de Tagaste, S. (2007). Ciudad de Dios. Madrid: Gredos.

Ángel, D. (2015). El tiempo de la memoria. Revista de Estudios de Filosofía (en revisión).

Attenburrow, M. E. J., Cowen, P. J., \& Sharpely, A. $L$ (1996). Low dose melatonin improves sleep in healthy middle-aged subjects. Psychopharmacology, 126, 179 - 181

Augé, M. (1998). Las formas del olvido. Barcelona: Gedisa.

Bayés, R. (2000). Una estrategia para la detección del sufrimiento en la práctica clínica. Revista de la sociedad española del dolor, 7, 70-74.

Bayés, R. (2001). Psicología del sufrimiento y de la muerte. Barcelona: Martínez Roca.

Bergson, H. (1972). El pensamiento y lo moviente. Buenos Aires: La Pléyade.

Bergson, H. (1999). Matéria e memória: ensaio sobre a relação do corpo com o espírito. São Paulo: Martins Fontes.

Buijs, R. M., \& Kalsbeek, A. (2001). Hypothalamic integration of central and peripheral clocks. Nature Reviews Neuroscience, 2, 521-526

Cassone, V. M. (1990). Effects of melatonin on vertebrate circadian systems. Trends in Neurosciences, 13(11), 457 - 467

Cole, A. (1994). Doing life history research in theory and in practice. New Orleans: Paper prepared for the annual meeting of the American Educational Research Association.

Del Palacio, M., Alvarez, S., \& Muñoz, M. (2012). HIV-1 infection and neurocognitive impairment in the current era. Revista Médica de Virología, 22(1), 33-45.

Forsyth, B. (2003). Psychological aspects of HIV infection in children. Child and Adolescent Psychiatric Clinics, 12, 423- 437.

Foster, C., \& Lyall, E. (2005). Children with HIV: improved mortality and morbidity with combination antiretroviral therapy. Current Opinion in Infectious Diseases, 18, 253-259.

Foster, C., Biggs, R., Melvin, D., Walters, M., Tudor, G., \& Lyall, E. (2006). Neurodevelopmental outcomes in children with HIV infection under 3 years of age. Developmental Medicine \& Child Neurology. 48(8), 677-682.

Gómez, T. (2014). Historia del reloj primer reloj de péndulo tipos y evolución. Recuperado el 11 de noviembre de 2015, de PIONEROS, Inventos y Descubrimientos claves de la historia: http://historiaybiografias.com/reloj/

Gómez, M., \& Grau, J. (2006). Dolor y sufrimiento al final de la vida. Madrid: Arán.

González, M., Ambrosio, K., \& Sánchez, S. (2006). Regulación neuroendócrina del hambre, la saciedad y el mantenimiento del balance energético. Artemisa VIII(3), 191 - 200.

Grau, J. (2003). La identificación del sufrimiento: perspectivas para la psicología de la salud. Memorias del II congreso latinoamericano de psicología de la salud. Cartagena de Indias, Colombia: ALAPSA .

Grau, J. (2004). Sufrimiento y tiempos de espera en pacientes oncológicos: una metodología evaluativa. Congreso Iberoamericano de Santiago de Chie, conferencia magistral. Santiago de Chile.

Jaspers, K. (1980). Origen y meta de la historia. Madrid: Alianza.

Kant, I. (2007). Crítica de la razón pura, trad. de M. Caimi. Buenos Aires: Colihue. 
Lavie, P. (2001). Sleep-wake as a biological rhythm. Annual Review of Neuroscience, 52, 277 - 303

Llantá, M. C., Grau, J., Massip, C., Pire, T., Rivero, M., \& Ortiz, G. (2005). La esperanza en el paciente oncológico: hacia una reconceptualización. Psicología de la salud, 15(2), 187 - 194.

Llantá, M., Grau, J., \& Massip, C. (2004). Evaluación el tiempo de espera y sufrimiento en pacientes con cáncer y su familia. Proyecto inédito de investigación - CITMa. La Habana: INOR.

Luhmann, N. (1998). Sistemas Sociales, Lineamientos para una teoría general. Bogotá D.C.: Centro Editorial Pontificia Universidad Javeriana.

Marramao, G. (2008). Kairós - apología del tiempo oportuno. Barcelona: Gedisa.

McCoig, C., Castrejon, M., \& Castano, E. (2002). Effect of combination antiretroviral therapy on cerebrospinal fluid HIV RNA, HIV resistan$\mathrm{ce}$, and clinical manifestations of encephalopathy. Journal of Pediatrics, 141, 36-44.

Mendez, J., \& Grau, J. (2003). La evaluación psicológica en el enfermo al final de la vida: principios y técnicas. La evaluación del sufrimiento y de la calidad de vida. En M. G.-S. (Ed.), Avances en cuidados paliativos (págs. 151 - 170). Las Palmas de la Gran Canaria: Gafos.

Merriam, S. (1988). Case study research in education: Aqualitative approach. San Francisco CA: Jossey - Bass.

Moore, R. Y. (1996). Neural control of the pineal gland. Behavioural Brain Research, 73, $125-130$

Organización Internacional de Trabajo -OIT-. (13 de junio de 2005). $93^{a}$ Conferencia Internacional del Trabajo Las jornadas de trabajo en todo el mundo: el equilibrio entre flexibilidad y protección. Recuperado el 26 de diciembre de 2015, de Organización Internacional del Trabajo: http://www.ilo.org/global/aboutthe-ilo/newsroom/news/WCMS_075267/lang-es/index.htm

Piaget, J. (1964). Seis estudios de psicología. Barcelona: Editorial Labor.

Piaget, J. (1978). El desarrollo de la noción de tiempo en el niño. México: Fondo de Cultura Económica.

Pinel, J. (2007). Biopsicología. 6ta. Edición. Madrid: Person Educación, SA. Pag 391

Richter, H., Torres-Farfán, C., Rojas-García, P., Campino, C., Torrealba, F., \& Serón-Ferré, M. (2004). The circadian timing system: making sense of day/night gene expression. Biological Research, 37(1), 11-28.

Ricœur, P. (2004). La memoria, la historia, el olvido. Buenos Aires: Fondo de Cultura Económica.

Rowlatt, J. (26 de octubre de 2014). Por qué es tan precisa la hora actual. Recuperado el 11 de noviembre de 2015, de BBC: http://www. bbc.com/mundo/noticias/2014/10/141022 economia_elemento_quimico_cesio_relojes_ hora_exacta_finde_kv

Sanchez, J. (2017). El aporte del sistema biológico, psíquico y social a la construcción de la temporalidad en niños con VIH. Revista Mad, (36), 72-87. doi:10.5354/0718-0527.2017. 46143

Sánchez, J., Vasco, C. \& Restrepo, F. (2017). La construcción de la temporalidad en niños y niñas con VIH. Manizales: Universidad de Manizales.

Saper, C. B., Chou, T. C., \& Scammell. T. E. (2001) The sleep swith: Hyphothalamiccontrol of sleep and wakefulness. Trends in Neurosciences, $726-731$

Serna, J. (2009). Somos tiempo. Barcelona: Anthropos. 
Smith, R., Chernoff, M., Williams, P., Malee, K., Sirois, P ... Rutstein, R. (2012). Impact of HIV severity on cognitive and adaptive functioning during childhood and adolescence. The Pediatric Infectious Disease Journal, 31(6), 592-598, Doi: 10.1097/INF.0b013e $318253844 b$

Smith, R., Malee, K., \& Leighty, R. (2006). Effects of perinatal HIV infection and associated risk factors on cognitive development among young children. Pediatrics, 117, 851-862.

Stake, R. (1994). Case studies. En N. K. (Eds.) (Ed.), Handbook of qualitative research (págs. 236 247). Thousand Oaks, CA: Sage.

Stake, R. (1995). The art of case study research. Thousand Oaks, CA: Sage.
Stake, R. (1998). Investigación con estudio de casos. Madrid: Morata.

Valenzuela, F., Torres, C., Richter, H., Méndez, N., Campino, C. ... Serón-Ferré, M. (2008). Clock gene expression in adult primate suprachiasmatic nuclei and adrenal: is the adrenal a peripheral clock responsive to melatonin? Endocrinology, 149(4), 1454-1461. doi: 10.1210/ en.2007-1518

Van Essevelt, L. E., Lehman, M. N., \& Boer, G. J. (2000). The suprachismatic nucleus and the circadian time - keeping system revisited. Brain Research Review, 33, 34 - 77

Vasco, C. E. (2000). El problema del tiempo. Medellín: Editorial Universidad Nacional de Colombia, Sede Medellín, facultad de ciencias humanas y económicas. 